\title{
La diplomacia pública como herramienta de política exterior. Alcances teóricos y perspectiva peruana
}

\author{
Public diplomacy as a foreign policy tool. Theoretical scope and the \\ Peruvian perspective
}

\section{ALEJANDRO PAREDES MORENO}

Magíster en Relaciones Internacionales, diplomacia por la Academia Diplomática del Perú Javier Pérez de Cuéllar y bachiller en Derecho por la Universidad de Lima. Tercer secretario del Servicio Diplomático de la República. Actualmente trabaja en la Dirección General para Asuntos Culturales del Ministerio de Relaciones Exteriores. 



\title{
La diplomacia pública como herramienta de política exterior. Alcances teóricos y perspectiva peruana \\ Public diplomacy as a foreign policy tool. Theoretical scope and the Peruvian perspective
}

\author{
Alejandro Paredes Moreno \\ UNIVERSIDAD DE LIMA \\ alejandroparedesmoreno@gmail.com
}

\section{PALABRAS CLAVE / KEYWORDS}

Diplomacia pública / diplomacia de nicho / estrategias de política exterior / comunicación política / poder blando / poder inteligente

Public diplomacy / niche diplomacy / political communication / foreign policy strategies / soft power / smart power.

\section{SUMILLA}

La diplomacia pública, considerada como elemento central en el diseño y ejecución de estrategias modernas de política exterior, tiene como elemento central el nuevo paradigma de las comunicaciones y la multiplicidad de actores que se ven potenciados por él. En tal tenor, un estudio teórico de este tipo de diplomacia, así como un trabajo perspectivo para el caso peruano -que busque sentar las bases para el diseño de una estrategia nacional al respecto-, es central para poder impulsar nuestra política exterior en todo ámbito, a través del uso coherente de nuestras potencialidades y búsqueda de nichos que mejoren nuestras capacidades en la arena internacional.

\section{ABSTRACT}

Public diplomacy, as a central element in the design and execution of foreign policy strategies, has as its central element the new paradigm of communications and the multiplicity of actors that are empowered by it. In that sense, a theoretical study of this type of diplomacy; as well as a perspective work for the Peruvian case -which seeks to lay the foundations for the design of a national strategy in this regard- is central to be able to promote our foreign policy in all areas, through the coherent use of our potential and search for niches to improve our capabilities in the international arena 


\section{Introducción}

La diplomacia pública es un instrumento de valor estratégico orientado a la obtención de los fines, objetivos e intereses de política exterior de los Estados y otros actores internacionales, a través de la configuración y proyección de la imagen pública de los mismos. En la actualidad, debido a la creciente influencia de la opinión pública aunada al avance exponencial de las Tecnologías de Información y Comunicación (TIC), todo país se debería plantear una estrategia de comunicación política para alcanzar presencia en la arena internacional en nichos específicos que tengan un correlato interno.

Esta forma de ejercer la diplomacia, la cual engloba el concepto de diplomacia cultural, debe ser idealmente diseñada por los entes públicos encargados de la política exterior de los Estados u otros actores internacionales -que en el caso peruano sería el Ministerio de Relaciones Exteriores (MRE)-; sin embargo, este concepto no está siempre integrado en las políticas sectoriales de los entes públicos, lo cual genera una desventaja ante países que ya han desarrollado una estrategia holística al respecto.

En tal sentido, a través de estas líneas intentaremos evidenciar la relevancia y necesidad de establecer una estrategia institucional de este tipo de diplomacia -tanto para el caso peruano, como para mos que el uso sistemático de sus herramientas e instrumentos es preponderante para fortalecer y consolidar la presencia e imagen de cualquier país ante la comunidad internacional.

Con este objetivo, sintetizaremos los principales alcances teóricos de la diplomacia pública, con la finalidad de entender el concepto en el marco de la diplomacia, las relaciones internacionales y la política internacional; proseguiremos con un análisis esquematizado de la diplomacia pública peruana, partiendo de sus actores, planes y funciones; y, finalmente, esbozaremos, en concordancia con los objetivos de política exterior peruanos detallados en nuestros instrumentos de política y gestión pública-, una posible estrategia de diplomacia de nicho -concepto relacionado al de diplomacia pública-, plasmada en mensajes estratégicos, mediante los cuales el Perú podría liderar espacios en el plano internacional.

\section{Concepto y alcances teóricos de la diplomacia pública}

El concepto de diplomacia pública fue inicialmente desarrollado por el profesor Edmund Gullion en 1965 (Azpíroz Manero, 2011, p.26) (Tejada Florez, 2013, p.13) (Cull, 2009, p.63) (Manfredi Sánchez, 2010, p.3) (Noya, 2006, p.2), que si bien correspondía prevalentemente al concepto de diplomacia tradicional, este resaltaba características que presentan puntos y elementos de contacto con la 
diplomacia pública como tal, específicamente en aspectos como el nivel de difusión, la forma en que esta es ejercida, el cuidado de la opinión pública foránea, una variedad más amplia de partes involucradas y de destinatarios, así como un contenido más amplio (Paredes Moreno, 2018, p.179).

Conceptualmente, la diplomacia pública fue considerada preponderantemente como una parte accesoria de la diplomacia tradicional, no indispensable mientras esta cumpliese satisfactoriamente su finalidad. Actualmente, es evidente que factores ineludibles, como por ejemplo los avances tecnológicos, han influenciado sea en el concepto como en la práctica de la diplomacia, otorgando a la diplomacia pública un rol relevante en el actual escenario diplomático mundial (Manfredi Sánchez, 2014, p.21). Países como EE.UU., Canadá, Brasil, México y Chile, por mencionar algunos del continente americano, cuentan con un plan de diplomacia pública activa (Méndez-Coto, 2016, p.85).

Con la finalidad de entender holísticamente el concepto de diplomacia pública, creemos necesario desagregar aspectos inherentes al mismo; en tal sentido, consideramos relevante analizar sus características, objetivos, actores, elementos, tipos y áreas de acción.

En base a un ejercicio sintetizador y sistematizador de los rasgos que caracterizan a la diplomacia pública, podemos decir que este tipo de diplomacia tiene diez características principales, las cuales pueden ser apreciadas en la figura 1.

En cuanto a los objetivos de la diplomacia pública, es necesario partir de la premisa de que esta aporta nuevos y diferentes niveles a la actividad diplomática, incluyendo la participación de nuevos actores con la capacidad de influenciar en los diferentes y variados ámbitos de las relaciones internacionales, conduciéndola así a un replanteamiento de la diplomacia acorde con la nueva estructura de dichas relaciones, sirviéndose en el proceso de las nuevas herramientas y tecnologías.

En función de lo expuesto, podemos decir que la diplomacia pública tiene múltiples objetivos que difieren entre cada actor internacional, siendo el principal el ejercicio de la influencia de un actor o entidad internacional sobre un público extranjero, utilizando para este propósito diversas estrategias de comunicación que incluyen programas educativos, informativos y de entretenimiento, a fin de cumplir los diversos propósitos de política exterior de dicho actor (Manfredi Sánchez, 2011, p.211) (Noya, 2006, p.6).

Podemos considerar tres objetivos principales de la diplomacia pública. El primero sería la mejora de la economía mediante el reconocimiento e impulso de la marca país con el propósito de impulsar la inter- 
Figura 1. Características de la diplomacia pública

Es una actividad comunicativa, pública, política, estratégica y de carácter internacional (Azpíroz Manero, 2011, p.23) (Morillo Herrada, 2012, p.34).

Es complementaria a la diplomacia tradicional, garantizando la continuidad de los vínculos y cauces de comunicación formal entre países (Noya, 2006, p.6) (Manfredi Sánchez, 2010, p.3) (Gullion, 1965) (Portugal Sánchez, 2001, p.249-253).

Es policéntrica, es decir, funciona fuera del nivel estrictamente gubernamental y los emisores, tanto públicos como privados, son múltiples; $y$ heterárquica, lo que implica que debido a la multiplicidad de actores que la practican no siempre se sigue un lineamiento jerárquico o una imagen ordenada de lo que se quiere proyectar (Noya, 2006, p.24) (Portugal Sánchez, 2001) (Azpíroz Manero, 2011, p.28-32) (De los Rios Diez, 2012, p.13) (Gregory, 2011, p.353).

Tiene a la opinión pública internacional como principal audiencia (Azpíroz Manero, 2011, p.32) (De los Rios Diez, 2012, p.13) (Manfredi Sánchez, 2010, p.3) (Gullion, 1965) (Tuch, 1990, p.3). Sin embargo, no siempre está dirigida a un público general o sino muchas veces apunta a individuos y objetivos específicos (Cull, 2009, p.57).

Se apoya en un flujo de información abierto, transparente, estable y creible (Manfredi Sánchez, 2010) (Azpíroz Manero, 2011, p.32) (De los Rios Diez, 2012, p.13), el cual, hoy en día, es impulsado y potenciado por las TIC (Terrés, 2011, p.118-119) (Blog Diplomacia Pública del Ministerio de Relaciones Exteriores del Perú, 2012).

Se apoya en un proceso mutuo de entendimiento (bidireccional) entre los emisores y receptores de la diplomacia pública (De los Rios Diez, 2012, p.21) (Cull, 2010, p.12) (Portugal Sánchez, 2001, p.249-253).

Utiliza herramientas de soft power como los valores, la cultura, las tradiciones, para promover, informar y difundir la imagen de un Estado o ente internacional emisor, para lograr objetivos de política exterior (Terrés, 2011, p.119) (Agencia de Información de los Estados Unidos [USIA], 2004) (Gullion, 1965) (Tuch, 1990, p.3) (Department of State Library , 1987, p.85) (Nieto y Peña, 2008, p.149) (Portugal Sánchez, 2001, p.249-253); sin embargo, también puede servir a fines de hard power (Melissen, 2005, p.14).

Busca influenciar en la opinión pública de otros países en la dirección que marquen los objetivos del actor emisor (Gullion, 1965) (Department of State Library , 1987, p.85) (Department of State Library, 1987, p.28) (Manheim, 1994) (Noya, 2006, p.3) (Cull, 2009, p.57) (Mor, 2007, p.667) (La Porte, 2007, p.26).

Prioriza los contactos P-t-P y G-t-P (Azpíroz Manero, 2011, p.30) (Manfredi Sánchez, 2010, p.5).

Involucra un planeamiento, estrategia y ejecución de una política específica (Morillo Herrada, 2012, p.34) (Azpíroz Manero, 2011, p.23) (Noya, 2006, p.3) (Nieto y Peña, 2008, p.161) (Oviamionayi lyamu, 2004, p.215-216) (Portugal Sánchez, 2001, p.249-253).

Elaboración propia en base a múltiples autores citados en la tabla y Paredes Moreno, 2018, p.35.

nacionalización y el comercio exterior. Un segundo objetivo es el reforzamiento de la identidad nacional, mientras que el tercer objetivo es el de incrementar la influencia de un Estado en el público extranjero (Manfredi Sánchez, 2011, p.211-215) (Man-
En el desarrollo de las estrategias orientadas al cumplimiento de sus diversos objetivos, la diplomacia pública requiere de la participación de múltiples actores, los cuales, según su nivel de interacción, podemos dividir de acuerdo a las siguientes figuras: 
Figura 2. Actores -emisores- de la diplomacia pública

\begin{tabular}{|c|c|}
\hline \multicolumn{2}{|r|}{ Emisores } \\
\hline Actores & Descripción \\
\hline $\begin{array}{l}\text { Estados y servidores } \\
\text { públicos }\end{array}$ & $\begin{array}{l}\text { A través de sus Ministerios de Relaciones Exteriores, otros ministerios (cultura, } \\
\text { educación, economía, turismo), funcionarios diplomáticos u otros funcionarios } \\
\text { estatales (De los Rios Diez, 2012, p.16) (Tejada Florez, 2013, p.34) (Department } \\
\text { of State Library, 1987, p.85) (Morillo Herrada, 2012, p.34) (Oviamionayi lyamu, } \\
\text { 2004, p.215-216) (Mor, 2007, p.667) (Gregory, 2011, p.353) (Blog Diplomacia } \\
\text { Pública del Ministerio de Relaciones Exteriores del Perú, 2012) (Portugal } \\
\text { Sánchez, 2001, p.249-253). }\end{array}$ \\
\hline $\begin{array}{l}\text { Organizaciones } \\
\text { internacionales y sus } \\
\text { funcionarios }\end{array}$ & $\begin{array}{l}\text { Hay una tendencia a que las organizaciones internacionales cuenten con } \\
\text { un departamento de diplomacia pública, los cuales persiguen objetivos } \\
\text { específicos y de acuerdo a sus intereses propios, que pueden o no coincidir } \\
\text { con los de los Estados que los conforman (Cull, 2009, p.60) (Rubio, 2014, p.13) } \\
\text { (Azpíroz Manero, 2011, p.28) (Noya, 2006, p.3) (Manfredi Sánchez, 2010, p.5) } \\
\text { (Gregory, 2011, p.353). }\end{array}$ \\
\hline $\begin{array}{l}\text { Organizaciones No } \\
\text { Gubernamentales (ONG) y } \\
\text { sus funcionarios }\end{array}$ & $\begin{array}{l}\text { Hoy en día, las ONG son una maquinaria activa de diplomacia pública con } \\
\text { relación a sus objetivos específicos e intereses propios. Estos muchas veces } \\
\text { pueden o no coincidir con los de los Estados en donde desempeñan sus } \\
\text { actividades (Cull, 2009, p.60) (Rubio, 2014, p.13) (Terrés, 2011, p.112) (Manfredi } \\
\text { Sánchez, 2011, p.201) (Azpíroz Manero, 2011, p.28) (Noya, 2006, p.3) (Manfredi } \\
\text { Sánchez, 2010, p.5) (Gregory, 2011, p.353). }\end{array}$ \\
\hline $\begin{array}{l}\text { Administraciones } \\
\text { territoriales }\end{array}$ & $\begin{array}{l}\text { Se trata de comunidades autónomas y entes locales que llevan a cabo } \\
\text { estrategias de diplomacia pública a través de la promoción turística, cultural, } \\
\text { educativa y cooperación (Melgar, 2012, p.51-52) (Rubio, 2014, p.12). }\end{array}$ \\
\hline $\begin{array}{l}\text { Asociaciones, empresas e } \\
\text { individuos influyentes }\end{array}$ & $\begin{array}{l}\text { Dentro de esta categoría de actores se puede destacar a las universidades, } \\
\text { think tanks, asociaciones profesionales, deportistas de alto nivel, artistas, } \\
\text { miembros del mundo de la cultura, entre otros personajes influyentes. Su } \\
\text { importancia radica en que generalmente cualquier labor que estos lleven a cabo } \\
\text { en el campo de la imagen-país será de antemano recibida como desinteresada, } \\
\text { independiente, objetiva y confiable. Por otro lado, también tenemos a las } \\
\text { empresas privadas que muchas veces apuestan por una incitativa pública de } \\
\text { imagen o marca país; al respecto, estas gozan de gran aceptación por parte de } \\
\text { públicos extranjeros (Melgar, 2012, p.51-52) (Rubio, 2014, p.13) (Terrés, 2011, } \\
\text { p.110-112) (Manfredi Sánchez, 2011, p.201) (Martinez Lopez, 2015, p.15). }\end{array}$ \\
\hline $\begin{array}{l}\text { Emigrantes e individuos } \\
\text { en general }\end{array}$ & $\begin{array}{l}\text { En esta categoría podemos encontrar tanto a los emigrantes del país } \\
\text { emisor como a los que viajan o residen en el país emisor. En ese sentido, } \\
\text { estas personas cumplen la labor de proyectar una imagen personal del país } \\
\text { de donde provienen o se llevan una imagen del país a donde emigraron, } \\
\text { es decir, practican la diplomacia P-t-P (Rubio, 2014, p.13) (Melgar, 2012, } \\
\text { p.51-52) (Manfredi Sánchez, 2010, p.5). Hoy en día, con el auge de las TIC y, } \\
\text { específicamente, el apogeo de las redes sociales, cualquier individuo puede } \\
\text { extrapolar su experiencia o interés a nivel global, en su país o en el extranjero. }\end{array}$ \\
\hline
\end{tabular}

Elaboración propia en base a múltiples autores citados en la tabla y Paredes Moreno, 2018, p.41. 
Figura 3. Actores -receptores- de la diplomacia pública

\begin{tabular}{|c|l|}
\hline \multicolumn{2}{|c|}{ Receptores } \\
\hline Actores & \multicolumn{1}{c|}{ Descripción } \\
\hline $\begin{array}{c}\text { Opinión pública } \\
\text { internacional }\end{array}$ & $\begin{array}{l}\text { Las estrategias de diplomacia pública muchas veces están dirigidas a la opinión } \\
\text { pública internacional en general, con el objetivo, no específico, de mejorar la } \\
\text { imagen y percepción del emisor (De los Rios Diez, 2012, p.18) (Azpíroz Manero, } \\
\text { 2011, p.29) (Gullion, 1965) (Tuch, 1990, p.3) (Department of State Library, 1987, } \\
\text { p.85) (Cull, 2009, p.57) (La Porte, 2007, p.26). }\end{array}$ \\
\hline $\begin{array}{c}\text { Grupo específico de sujetos } \\
\text { dentro de uno o varios } \\
\text { Estados / Organización } \\
\text { internacional / ONG, entre } \\
\text { otros }\end{array}$ & $\begin{array}{l}\text { Cuando existen objetivos especificos de política exterior, las políticas de } \\
\text { diplomacia pública son dirigidas a grupos de individuos que forman parte } \\
\text { de diversos sujetos de derecho internacional, ya que estos son los capaces } \\
\text { de influir directamente en los intereses del emisor (Cull, 2009, p.57) (Blog } \\
\text { Diplomacia Pública del Ministerio de Relaciones Exteriores del Perú, 2012) } \\
\text { (Gregory, 2011, p.353). }\end{array}$ \\
\hline \multirow{2}{*}{ Estados } & $\begin{array}{l}\text { Si bien los Estados son un receptor natural de la diplomacia en general, estos, } \\
\text { a través de sus departamentos de comunicaciones o diplomacia pública, } \\
\text { embajadas, consulados y representaciones permanentes, son los encargados } \\
\text { de captar, aunque no sean dirigidos hacia estos entes públicos, las estrategias } \\
\text { de diplomacia pública externa para reaccionar a ella. }\end{array}$ \\
\hline
\end{tabular}

Elaboración propia en base a múltiples autores citados en la tabla y Paredes Moreno, 2018, p.42.

Así también, es importante señalar que para que una estrategia de diplomacia pública se lleve a cabo, se requiere de la coordinación de cinco elementos indispensables y estrechamente vinculados: (i) una interpretación activa del entorno, lo cual se puede lograr a través de herramientas de medición de la opinión pública, análisis de tendencias y sociología de los países; (ii) un método de trabajo, el cual facilitará el cumplimiento de los objetivos marcados; (iii) posicionamiento, lo cual responde a la pregunta ¿cómo se quiere ser percibido; (iv) una narrativa, la cual, una vez trazado el objetivo, se encarga de diseñar un discurso estratégico para tal fin; y (v) coherencia o consistencia entre los mensajes y las acciones en el externo (Manfredi Sánchez, 2011, p.217-218).

Estos cinco elementos pueden ser enmarcados dentro de los tres grandes ámbitos de acción de la diplomacia pública: información, difusión y promoción, haciendo uso de las nuevas herramientas que donan los medios de comunicación, consideradas para este fin como un eje estratégico para la generación de los mensajes y su empleo al servicio de la diplomacia pública (De los Rios Diez, 2012, p.26).

Siguiendo esta línea de ideas, es necesario clasificar la práctica de la diplomacia pública en tres tipos: (i) la diplomacia cultural, que tiene como objetivo el refuerzo de la identidad a través de la ejecución de 
políticas de tipo cultural y educativo con la participación de entes y organismos, ya sean locales o foráneos; (ii) la diplomacia marca-país, que intenta promover una imagen positiva de un Estado de cara a la opinión pública internacional usando herramientas de la mercadotecnia como el branding, transformándola en nation branding o place branding; y (iii) la diplomacia de nicho, que plantea estrategias orientadas a desarrollar relevancia en materias, temas u objetivos determinados para audiencias específicas, aprovechando las "ventajas comparativas" internas que un actor internacional pueda explotar en la escena global (Azpíroz Manero, 2011, p.41) (Paredes Moreno, 2018, p.181).

En modo de completar los lineamientos en los cuales se enmarca la diplomacia pública, consideramos necesario mencionar algunos conceptos relacionados a su definición y, por ende, a su práctica. En primer lugar tenemos la propaganda, considerada una forma unidireccional de comunicación, que no genera dialogo y está sujeta al uso de contenidos que pueden ser falsos o producto de prácticas de desinformación, y que en consecuencia propende a la manipulación del receptor (Azpíroz Manero, 2011, p.24-25) (García de Alba, 2010, p.222) (La Porte, 2007, p.55) (Azpíroz Manero, 2011, p.8,31,36) (Noya, 2006, p.8) (Tejada Florez, 2013, p.15) (La Porte, 2007, p.55) (Cull, 2009, p.72).

En segundo lugar podemos mencionar al poder blando, entendido como la habili- dad para obtener objetivos usando la seducción o atracción, no por medio de la coerción o pago, sino más bien a través de medios culturales e ideológicos (Nye, 2004) (Saavedra Torres, 2012, p.139) (Kagan, 2003) (Nye, 2003).

Y en tercer lugar, como concepto que se identifica en forma más adecuada con la diplomacia pública, tenemos al poder inteligente, en el cual se combinan y utilizan las posibilidades y estrategias del poder duro y del poder blando (Nye, 2006) (Powe11 y Manfredi, 2014, p.6o) (Cull, 2009, p.61).

Finalmente, y teniendo en cuenta la multiplicidad de aportes teóricos analizados, podríamos definir a la diplomacia pública como una estrategia holística de comunicación exterior, creada al interior de un actor internacional, con la finalidad de proyectar, informar, promover o difundir -a través del entendimiento mutuo y sustento del mensaje- una imagen o idea que logre concretar las aspiraciones de política exterior de dicho actor internacional. Esta estrategia, en base al objetivo buscado, está dirigida a sectores generales o específicos -opinión pública internacional en general, público de un país en particular o nichos específicos del público internacional-, usando para ello, además de mecanismos tradicionales de la diplomacia - contacto G-t-G y D-t-D-, estrategias de vinculación P-t-P y G-t-P, potenciados, hoy en día, por las TIC, para así influenciar a los receptores previamente identificados (Paredes Moreno, 2018, p.178). 


\section{Actores de la diplomacia pública peruana}

De acuerdo a lo señalado en los alcances teóricos del presente artículo, existen múltiples actores, incluso al interior de los actores internacionales, que configuran, mediante un plan general o individualmente, una proyección pública propia. Así pues, estos actores, públicos o privados, nacionales o internacionales, pueden, en algunos casos, no tener integrado o conocer el concepto de diplomacia pública, aunque en la práctica lo estén aplicando.

En tal sentido, se mencionará a los principales actores, públicos y privados, involucrados en la práctica y configuración de la diplomacia pública en el Perú. Para esto se tomará como referencia el trabajo y método desarrollado en la tesis: "La diplomacia pública peruana - análisis de sus actores y propuesta de mensajes estratégicos que contribuyan a la consecución de algunos objetivos de política exterior" (Paredes Moreno, 2018), sintetizando sus principales hallazgos y complementándolos con la anexión de los medios de comunicación estatales: Agencia de Noticias Andina y el Instituto de Radio y Televisión Peruana.
Estos actores, los cuales trabajan en el desarrollo de la imagen del Perú en el exterior, pueden ser públicos o privados. En el primer grupo se encuentran las instituciones del Estado que tradicionalmente tienen entre sus competencias la proyección, promoción o manejo de cara exterior del país, siendo los principales el $\mathrm{MRE}^{1}$, el Ministerio de Comercio Exterior y Turismo (Mincetur) ${ }^{2}$ y el Ministerio de Educación (Minedu), este último a través del Programa Nacional de Becas y Crédito Educativo (Pronabec). En el segundo grupo podemos encontrar a los gremios empresariales, empresas, Organizaciones No Gubernamental (ONG) y diversas personalidades que por su aporte representan la imagen del país (Paredes Moreno, 2018, p.75-132).

Es importante mencionar que estos actores, sean públicos o privados, han desarrollado lineamentos y procesos internos que responden a la proyección de la imagen del país en el exterior, por lo que son asimilables a objetivos de la diplomacia pública. Sin embargo, y considerando su importancia para el logro de objetivos de política exterior, estos procesos no son enmarcados ni organizados dentro del concepto básico de diplomacia pública, el

1 Dentro del Ministerio de Relaciones Exteriores (MRE) podemos encontrar las siguientes dependencias: (i) Dirección General de Estudios y Estrategias de Política Exterior, (ii) Dirección General para Asuntos Culturales, (iii) Oficina General de Comunicación, (iv) Dirección General de Comunidades Peruanas en el Exterior y Asuntos Consulares y $(v)$ embajadas del Perú en el exterior (teniendo como ejemplo a las misiones en Washington y Santiago de Chile).

2 Dentro del Ministerio de Comercio Exterior y Turismo (Mincetur) podemos encontrar las siguientes dependencias: (i) Comisión de Promoción del Perú para la Exportación y el Turismo (Promperú), (ii) Dirección de las Oficinas Comerciales del Perú en el Exterior, (iii) Oficinas Comerciales del Perú en el Exterior (OCEX) y (iv) Dirección de 
mismo que debería ser proporcionado por la Cancillería, de acuerdo a su rectoría en asuntos de política exterior, debiéndose coordinar una estrategia público-privada y multisectorial de diplomacia pública, en donde, teniendo en cuenta la multiplicidad de actores involucrados, se encargue del diseño, coordinación y ejecución de una estrategia general de este tipo de diplomacia.

En base a lo anterior, podemos decir que en el país no existe una estrategia general de diplomacia pública diseñada o coordinada por el MRE $u$ otra entidad del Estado. En este punto, es necesario resaltar el trabajo de las embajadas peruanas en EE.UU. y Chile, las cuales representan buenos ejemplos de un ejercicio de estrategias de diplomacia pública. Del mismo modo, la Oficina General de Comunicación del MRE viene elaborando el proyecto de plan de comunicación 2019-2021, en el que se incluirá el concepto de diplomacia pública.

\section{La diplomacia pública como herramienta de política exterior}

El Perú tiene y desarrolla actividades y trabajos constantes en el ámbito de política exterior y proyección internacional a través de instrumentos de política y gestión exterior, tales como la Sexta Política del Acuerdo Nacional, el Plan Bicentenario, el Plan Estratégico Sectorial Multianual del MRE 2015-2021, el Plan Estratégico Institucional de Promperú 2016-
2018 y el Plan Operativo Institucional del MRE 2018, todos estos relacionados entre sí y al mismo tiempo susceptibles de correlacionarse con mensajes estratégicos de la diplomacia pública (Paredes Moreno, 2018, p.135-174). Para este propósito, se podría realizar un trabajo estratégico más intenso de liderazgo sobre temas de relevancia internacional que representen especial importancia para nuestro país y sus objetivos de política exterior, a través del desarrollo y la implementación de una articulada estrategia de mensajes de diplomacia pública. Estos mensajes estratégicos, que pueden ser sintetizados y concordados con los instrumentos de política y gestión pública antes señalados, son los siguientes: 
Figura 4. Actores -receptores-de la diplomacia pública

\begin{tabular}{|c|c|}
\hline $\begin{array}{l}\text { Propuesta de mensajes estratégicos de } \\
\text { diplomacia pública }\end{array}$ & Contenido del mensaje \\
\hline $\begin{array}{l}\text { 1. Perú, líder regional en el respeto de los } \\
\text { valores democráticos, la paz y los dere- } \\
\text { chos humanos: Grupo de Lima, ayuda } \\
\text { humanitaria a venezolanos y operacio- } \\
\text { nes de paz. }\end{array}$ & $\begin{array}{l}\text { Unir estos tres temas (crisis democrática venezolana, ayuda } \\
\text { humanitaria y operaciones de paz en Venezuela) en un mensaje } \\
\text { estratégico de diplomacia pública, el cual demuestre nuestro lide- } \\
\text { razgo en esos ámbitos. Este mensaje se encontrará fuertemente } \\
\text { sedimentado en nuestro coherente actuar y definitivamente nos } \\
\text { catapultaría como un país confiable y guía en la materia. }\end{array}$ \\
\hline $\begin{array}{l}\text { 2. Perú, líder en integración sudamerica- } \\
\text { na, a través de los encuentros presiden- } \\
\text { ciales y gabinetes binacionales. }\end{array}$ & $\begin{array}{l}\text { La estrategia sintetizada en este mensaje debería estar dividida } \\
\text { en dos acciones específicas: (i) iniciativa y propuesta por parte del } \\
\text { Perú a los demás países, en conjunto, de poder compartir sus ex- } \\
\text { periencias a regiones o países que se encuentren atravesando si- } \\
\text { tuaciones de tensión, o simplemente quieran mejorar sus relacio- } \\
\text { nes bilaterales; y, una vez realizada esta acción, (ii) llevar, a través } \\
\text { de un plan conjunto y liderado por nuestro país, nuestro modelo al } \\
\text { exterior, brindando ponencias, asesorías y, en un futuro, diseño } \\
\text { de planes específicos para cada caso. }\end{array}$ \\
\hline $\begin{array}{l}\text { 3. Perú, país de dinamismo económico, } \\
\text { especialmente en la cuenca del pacífico: } \\
\text { Alianza del Pacífico, Foro de Cooperación } \\
\text { Económica Asia-Pacífico (APEC) }{ }^{*} \text { y Tra- } \\
\text { tado Integral y Progresista de Asociación } \\
\text { Transpacífico }(\text { Cptpp })^{* *} \text {. }\end{array}$ & $\begin{array}{l}\text { Se podría resaltar, a través de diferentes foros económicos in- } \\
\text { ternacionales como la Conferencia de las Naciones Unidas sobre } \\
\text { Comercio y Desarrollo (Unctad), el Centro de Comercio Interna- } \\
\text { cional, el Banco Mundial, el Fondo Monetario Internacional (FMI), } \\
\text { la Cámara de Comercio Internacional, el Foro Económico Mundial } \\
\text { (Davos), entre otros, nuestro papel, conjuntamente con México, } \\
\text { como únicos miembros de estos tres esfuerzos: APEC, Alianza } \\
\text { del Pacífico y Cptpp, y nuestro firme compromiso al libre comercio } \\
\text { y sus buenas prácticas. }\end{array}$ \\
\hline $\begin{array}{l}\text { 4. Perú, pais comprometido y líder en la } \\
\text { lucha contra el cambio climático. }\end{array}$ & $\begin{array}{l}\text { Una estrategia de diplomacia pública para este nicho específ- } \\
\text { co debería tener en cuenta los siguientes aspectos y acciones } \\
\text { específicas: (i) promoción del nombre ganado por nuestro país } \\
\text { en la Convención Marco de las Naciones Unidas sobre el Cam- } \\
\text { bio Climático (Cmnucc) y demás foros del ambiente, a través de } \\
\text { estrategias de difusión -conferencias, ponencias, entre otros-; } \\
\text { (ii) vinculación con la sociedad civil y de ONG especializadas, } \\
\text { mediante uso de las TIC y relación con las principales persona- } \\
\text { lidades y dirigentes de estas últimas; (iii) posicionamiento como } \\
\text { líder regional en la lucha contra el cambio climático, a través de } \\
\text { la Organización del Tratado de Cooperación Amazónica (OTCA) } \\
\text { y otros mecanismos regionales como la Organización de los Es- } \\
\text { tados Americanos (OEA), Alianza del Pacifico, Unión de Naciones } \\
\text { Suramericanas (Unasur) y Comunidad Andina; (iv) iniciativa de } \\
\text { creación, en el marco de la Cmnucc, de un grupo de países líderes } \\
\text { contra el cambio climático, en donde se podría integrar a Francia, } \\
\text { China, India, Irlanda, Costa Rica, Noruega y Reino Unido, en base a } \\
\text { su buen desempeño en la mitigación, prevención y vulnerabilidad; } \\
\text { y (v) estrategia de captación de los fondos establecidos para la } \\
\text { mitigación, reparación y prevención del acuerdo de París; dicho } \\
\text { plan deberá remarcar nuestra vulnerabilidad en los principales fo- } \\
\text { ros mundiales y ONG. }\end{array}$ \\
\hline
\end{tabular}




\begin{tabular}{|l|l|}
\hline Perú, país bicentenario. & $\begin{array}{l}\text { Una estrategia de diplomacia pública en este sentido debe sa- } \\
\text { ber aprovechar esta coyuntura favorable para impulsar objeti- } \\
\text { vos de política exterior en todo ámbito, con especial énfasis en } \\
\text { la mejora de las relaciones bilaterales y multilaterales, aumen- } \\
\text { to de la cooperación para el desarrollo, mejor posicionamiento } \\
\text { de la imagen-país, fortalecimiento de la identidad peruana en } \\
\text { nuestro llamado quinto suyo y extensión hacia una celebración } \\
\text { internacional. }\end{array}$ \\
\hline $\begin{array}{l}\text { Perú, país líder regional en la lucha contra } \\
\text { la corrupción. }\end{array}$ & $\begin{array}{l}\text { Nuestro país debe utilizar este flagelo que afecta a toda la re- } \\
\text { gión con la finalidad de, en concordancia con reformas internas } \\
\text { en la materia, liderar la lucha contra la corrupción en el ámbi- } \\
\text { to regional. En tal sentido, la organización o participación en } \\
\text { eventos internacionales con la temática de corrupción, como } \\
\text { lo fue la VIII Cumbre de las Américas, ayudará a nuestro país a } \\
\text { lograr tal objetivo. }\end{array}$ \\
\hline
\end{tabular}

Elaboración propia en base a Paredes Moreno, 2018, p.159-174.

* Asia-Pacific Economic Cooperation.

** Comprehensive and Progressive Agreement for Trans-Pacific Partnership.

Cabe recalcar que si bien el Perú ha realizado un importante y constante trabajo sobre estos temas, podría ejercer un trabajo estratégico más intenso para fines de proyección exterior y diplomacia pública, a través de narrativas a ser implementadas en el marco de alianzas bilaterales y multilaterales, sirviéndose de un plan de diplomacia pública y empleando adecuadas estrategias de difusión, información y promoción.

Es importante destacar que esta correlación entre los instrumentos de política y gestión exterior, y los mensajes estratégicos de diplomacia pública, encaja dentro del marco de la Política Nacional de Modernización de la Gestión Pública elaborada por Centro Nacional de Planeamiento Estratégico (Ceplan), principalmente en su fase estratégica, demostrándose la utilidad, conveniencia e importancia de su desarrollo como instrumentos principales o complementarios orientados a la obtención de importantes objetivos de política exterior peruana (Centro Nacional de Planeamiento Estratégico [Ceplan], 2015, p.11).

\section{Conclusiones y plan de acción}

A menara de conclusión, es importante mencionar que hoy en día la diplomacia pública, entendida como una herramienta estratégica de los actores internacionales para cumplir sus objetivos de política exterior, se ha convertido en un elemento neurálgico de la diplomacia de los Estados. En ese contexto, este tipo de diplomacia, el cual encaja y es potenciado por el nuevo paradigma de las comunicaciones, la diversificación de los actores internacionales y la opinión pública, tiene una especial relevancia en el proceso de 
análisis, diseño y formulación de estrategias y políticas para cualquier Cancillería moderna en el mundo.

En base a esta premisa, teniendo en cuenta los múltiples actores involucrados y con el propósito de desarrollar una proyección coherente en el ámbito internacional, consideramos oportuno elaborar algunas recomendaciones con la finalidad de poner en consideración elementos para el diseño de una estrategia institucional de diplomacia pública peruana.

Idealmente y proyectándonos ambiciosamente, la recomendación cardinal y más importante sería crear una Dirección General de Diplomacia Pública en el MRE (en adelante, la DDP), la cual se encargaría de elaborar, coordinar y ejecutar los planes estratégicos generales y específicos de diplomacia pública a nivel nacional e internacional.

Dicha dirección se encargaría de elaborar un plan estratégico general de diplomacia pública, con características puntuales, incorporando la ayuda técnica del Ceplan y de las demás dependencias del MRE. Así también, dicho plan estratégico deberá desarrollarse en concordancia plena con los objetivos definidos en los instrumentos y el carácter estratégico de nuestra política exterior, incorporando elementos multisectoriales, sean públicos o privados, y a través de propuestas de acciones y lineamientos, sean generales o específicos, en servicio de los men- sajes de la diplomacia pública peruana propuestos.

Para que este plan estratégico sea viable y efectivo es importante diferenciar estrategias por regiones y Estados, ser adaptable en el tiempo y de acuerdo a los cambios constantes en el contexto internacional, así como la inclusión de nuevos actores en el ámbito interno, por lo que deberá ser revisado en un periodo de tiempo no mayor de tres años.

De igual modo, en la elaboración del plan estratégico se deberá seguir un proceso ordenado, preciso y que considere como primer paso un análisis extenso por parte del MRE de los actores que se encontrarían involucrados en el diseño y ejecución de la diplomacia pública peruana, con la finalidad de realizar un mapeo de todos los actores que serán incluidos en su diseño.

Paso siguiente de este proceso seria la conformación de una mesa multisectorial -presidida por el MRE- con la inclusión de actores privados y públicos, con el propósito de establecer un mecanismo de coordinación y recoger información para el diseño del plan estratégico.

Por otro lado, la creación de la DDP implicaría, además, informar, instruir y actualizar a los servidores públicos del MRE y demás entidades públicas relacionadas, así como a instituciones privadas, que influyan en el diseño y ejecución de una futura estrategia de diplomacia pública, 
a través de capacitaciones, cursos y talleres, con el propósito de que se imparta conocimiento general y específico sobre la importancia de la diplomacia pública como un elemento estratégico para la política exterior del país y del Estado.

Por último, se deberán implementar los Departamentos de Diplomacia Pública en las misiones peruanas en el exterior más relevantes, identificadas previamente en el mencionado plan y de acuerdo al presupuesto disponible. Estos, a su vez, absorberán y englobarán los departamentos ya existentes en la mayoría de dichas misiones: (i) diplomacia cultural, (ii) digital y (iii) prensa.

\section{REFERENCIAS}

Azpíroz Manero, M. (2011). La Diplomacia Pública Estadounidense de la "Guerra Contra el Terror": Análisis y Evaluación de su Influencia en la Prensa Española (tesis doctoral). Facultad de Comunicación Departamento de Comunicación Pública - Universidad de Pamplona, Pamplona.

Blog Diplomacia Pública del Ministerio de Relaciones Exteriores del Perú. (2012). Diplomacia pública [Mensaje en un blog]. Recuperado de https://bit. ly/2HVoKqi

Centro Nacional de Planeamiento Estratégico (Ceplan). (2015). Directiva General del Proceso de Planemiento Estratégico - Sistema Nacional de Planeamiento Estratégico. Recuperado de https://bit.ly/2E6q85k
Cull, N. (2009). Diplomacia pública: Consideraciones teóricas. Revista mexicana de diplomacia pública, (85), 55-92.

Cull, N. (2010). Public diplomacy: Seven lessons for its future from its past. Place Branding and Public Diplomacy, 6, 1117. https://doi.org/10.1057/pb.2010.4

De los Rios Diez, A. (2012). El Rol del Ministerio de Relaciones Exteriores en la Diplomacia Pública: Los casos de Perú y Chile (tesis para obtener el grado de Magíster en Diplomacia y Relaciones Internacionales). Academia Diplomática del Perú, Lima.

Department of State Library. (1987). Dictionary of International Relation Terms. Washington D.C.: Department of State Library.

García de Alba Z., C. (2010). Diplomacia pública, propaganda y poder blando. $R e$ vista Mexicana de Política Exterior, (85), 221-228.

Gregory, B. (2011). American Public Diplomacy: Enduring Characteristics, Elusive Transformation. The Hague Journal of Diplomacy, 6 (3-4) 351-372. https:// doi.org/10.1163/187119111X583941

Gullion, D. E. (1965). About U.S. Public Diplomacy. Recuperado de https://bit. ly/1UXa62T

Kagan, R. (2003). Poder y Debilidad. Estados Unidos y Europa en el nuevo orden mundial. Madrid: Taurus .

La Porte, T. (2007). La diplomacia pública americana: Lecciones para una comunicación internacional. Comunicación y sociedad, XX (2), 23-59.

Manfredi Sánchez, J. L. (Octubre de 2010). Estrategia de comunicación y diplomacia pública. Hacia una nueva comunicación exterior regional. Segundo Congreso Internacional Comunicacíon 3.o. Universidad de Salamanca, Salamanca. 
Manfredi Sánchez, J. (2011). Hacia una teoría comunicativa de la diplomacia pública. Comunicación y Sociedad , 24 (2), 199-225.

Manfredi Sánchez, J. (2014). Competencias para la nueva diplomacia global. En E. Pérez de Ágreda, F. Rubio y J.L. Manfredi (Eds.), La Diplomacia Pública como reto de la política exterior (pp. 20-29). Madrid: Ministerio de Asuntos Exteriores y de Cooperación.

Manheim, J. (1994). Strategic Public Diplomacy \& American Foreign Policy. Oxford: Oxford University Press.

Martinez Lopez, F. (2015). La diplomacia deportiva y su inclusión como herramienta de acción de la política exterior en la Dirección de Relaciones Educativas y del Deporte del Ministerio de Relaciones Exteriores (tesis para obtener el grado de magister en Diplomacia y Relaciones Internacionales). Academia Diplomática del Perú, Lima.

Melgar, L. (2012). Diplomacia pública, un proyecto integral. En: Secretaría General Técnica del Ministerio de Asuntos Exteriores y de Cooperación (Eds.). Retos de nuestra acción exterior: Diplomacia pública y marca España (pp. 49-54). Madrid: Escuela Diplomática.

Melissen, J. (2005). The New Public Diplomacy, Soft Power in International Relations. New York : Palgrave macmillan. https://doi. org/10.1057/9780230554931

Méndez-Coto, M. (2016). Diplomacia pública y marca-país en las Américas: Un acercamiento a las experiencias de Brasil, Chile, México y Perú. Temas de Nuestra América, 32 (59), 81-98. https://doi.org/10.15359/tdna.32-59.6

Mor, B. (2007). The rhetoric of public diplomacy and propaganda wars: A view from self-presentation theory. European Journal of Political Research, 46 (5), 661-683. https://doi.org/10.1111/ j.1475-6765.2007.00707.x

Morillo Herrada, Z. R. (2012). Diplomacia y Comunicación: el desafio de la globalización. Loja: Universidad Técnica Particular de Loja.

Nieto, A. y Peña, M. (2008). La diplomacia pública: los medios de informativos como intrumento de política exterior. Estudios Políticos, (13,14,15), 149-163. https://doi.org/10.22201/ fcpys.24484903e.2008.0.18763

Noya, J. (2006). Una diplomacia pública para España (documento de Trabajo). Real Instituto Elcano, Madrid.

Nye, J. (2003). La paradoja del poder norteamericano. Madrid: Taurus.

Nye, J. (2004). Soft Power: The Means to Sucess in World Politics. New York: Public Affairs.

Nye, J. (19 de agosto de 2006). In Mideast, the Goal is 'Smart Power'. The Boston Globe. Recuperado de https://bit. ly/2WyQSYD

Oviamionayi Iyamu, V. (2004). Diplomacia pública en la bibliografía actual. Ámbitos, (11-12), 215-236.

Paredes Moreno, A. H. (2018). La diplomacia pública peruana - análisis de sus actores y propuesta de mensajes estratégicos que contribuyan a la consecución de algunos objetivos de política exterior (tesis para obtener el grado académico de Magíster en Diplomacia y Relaciones Internacionales). Academia Diplomática del Perú, Lima.

Portugal Sánchez, L. (2001). Diplomacia Pública Peruana: agregados de prensa y cultura. Lima: Universidad de Piura. 
Powell, C. y Manfredi, J. (2014). Innovación, diplomacia y think tanks. En E. Pérez de Ágreda, F. Rubio y J.L. Manfredi (Eds.), La Diplomacia Pública como reto de la política exterior ( $\mathrm{pp} .59$ 67). Madrid: Ministerio de Asuntos Exteriores y Cooperación - Escuela Diplomática de España.

Rubio, R. (2014). La diplomacia pública: Nuevos actores en un escenario nuevo. En E. Pérez de Ágreda, F. Rubio y J.L. Manfredi (Eds.), La Diplomacia Pública como reto de la política exterior (pp. 10-19). Madrid: Ministerio de Asuntos Exteriores y de Cooperación.

Saavedra Torres, J. (2012). El Poder Blando de la Marca País: Del Marketing a la Diplomacia Pública. Revista Digital de Marketing Aplicado, 5 (8), 133148 . https://doi.org/10.17979/redma.2012.01.08.4738

Tejada Florez, M. (2013). Diplomacia Pública Post Haya: Escenarios para la Construcción de Nuestra Relación con Chile (tesis para obtener el grado académico de magíster en Diplomacia y Relaciones Internacionales). Academia Diplomática del Perú, Lima.

Terrés, G. (2011). Diplomacia pública 2.0: una propuesta virtual para un mundo real. Revista Mexicana de Politica Exterior, (92), 98-126.

Tuch, H. (1990). Communicating with the World: US Public Diplomacy Overseas. New York: Palgrave Macmillan. https://doi.org/10.1007/978-1-34960512-5

Agencia de Información de los Estados Unidos (USIA). (2004). Public Diplomacy in the Context of Traditional Diplomacy. Recuperado de http://www.publicdiplomacy.org/45.htm 